\title{
GM mosquitoes fire first salvo against Zika virus
}

A Brazilian city in January became the first to approve a program to grow transgenic mosquitoes for their release into the environment as a public health measure against the Zika virus outbreak. The city of Piracicaba in Brazil said it would work in collaboration with the Milton Park, UK-based Oxitec to scale up release of transgenic Aedes aegypti mosquitoes, the main vector for the Zika, dengue and Chikungunya viruses, and build a new production facility there. With no Zika vaccine in sight, government officials across the globe are pondering strategies that suppress the mosquito populations to thwart the spread of infection. US and Chinese regulators both green-lighted field tests for vector control strategies involving nontransgenic Aedes albopictus mosquitoes.

Infections with the flavivirus Zika appear to be linked to a surge in the number of infants born with microcephaly, or abnormally small heads. Nearly 5,000 cases of microcephaly have been reported in Brazil since late last year, according to the Brazilian health ministry. Normally about 150 cases are reported there annually. "The link between Zika and microcephaly is very strong and comes from multiple lines of evidence," says Ernesto Marques, a public health scientist specializing in vaccines at the University of Pittsburgh in Pennsylvania.

The outbreak has spread fastest in Latin America, but has reached more than 33 countries. In response, the World Health Organization in January declared Zika an international public health emergency.

A handful of companies and institutes have begun working on a vaccine for Zika (Table 1). Brazil's Butantan Institute aims to develop a vaccine "in record time" and the US National Institute of Allergy and Infectious Diseases (NIAID) in January issued a call to the research community for Zika work. US President Barack Obama in February asked Congress for $\$ 1.8$ billion in emergency funding for vaccine development, mosquito control and public education.

But a vaccine is many years-and clinical trials-away. Some knowledge gained from vaccine work on other flaviviruses such as dengue, West Nile and yellow fever can be transferred to a Zika vaccine program, but to what extent is unclear. "We know very little about Zika," Marques says. "We don't know if a vaccine [for it] requires any special technology."

The only recourse, for now, is to fight the mosquitoes. Both $A$. aegypti and A. albopictus are likely Zika vectors, but $A$. aegypti

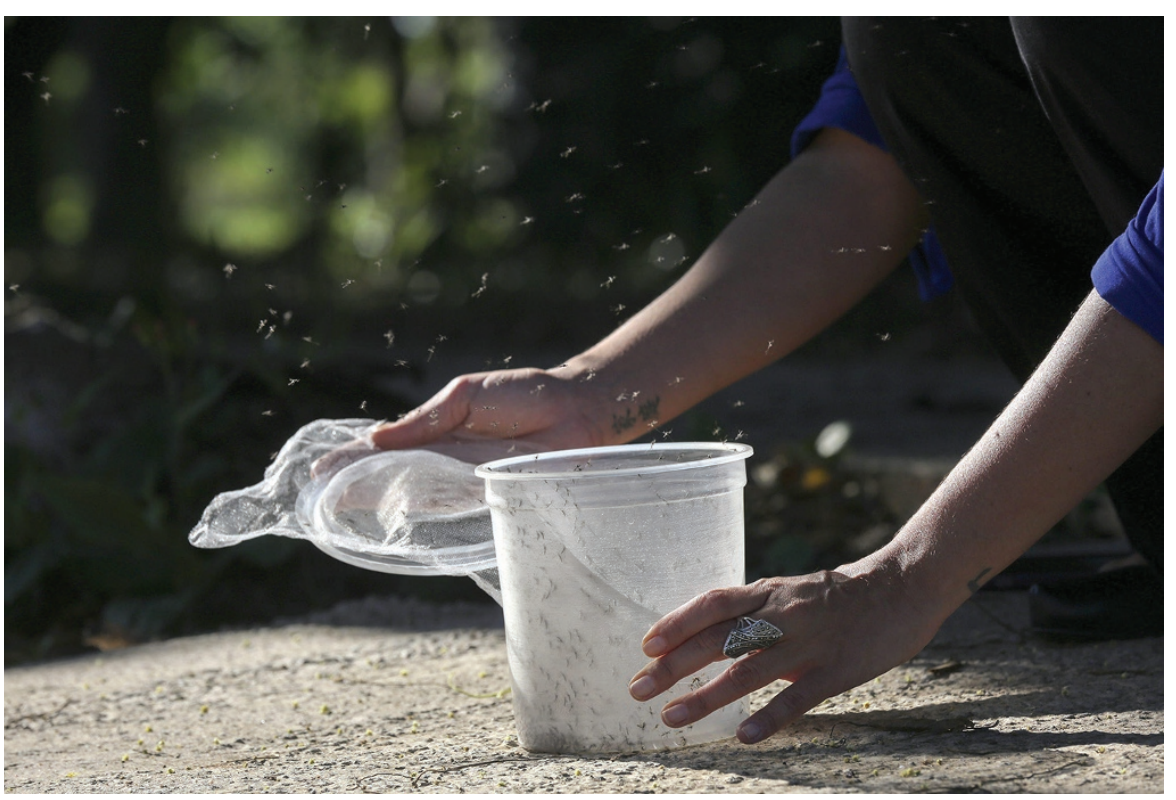

Genetically modified male Aedes aegypti mosquitoes made by Oxitec are released in Piracicaba, Brazil.

seems to be the primary culprit, says Tom Scott, an entomologist at the University of California (UC), Davis. Vector control is woefully difficult, however. In Zika-affected areas, local governments have been spraying insecticides, minimizing mosquito breeding grounds, urging the public to cover up and wear repellent, and asking women to delay becoming pregnant.

Entomologists worldwide have been busy reviewing biological approaches. A strategy used in agriculture, the sterile insect technique (SIT) involves the release of large numbers of radiation-sterilized insects to mate with and reduce wild pest populations. Although successful against several agricultural pests, the technique has not been as effective against mosquitoes. Researchers have also proposed using gene drives to force a genetic change in mosquitoes that make them unsuitable hosts for a pathogen or drive vector species to extinction. But gene drives are untested in the field and guidelines for responsible use haven't been hammered out.

The US and China are attempting to use mosquitoes sterilized, not by radiation, but by Wolbachia pipientis. The bacteria are introduced by microinjection followed by mass rearing. Mating of laboratory-reared males with wild females results in eggs that don't hatch due to loss of paternal chromosomes. Lexington, Kentucky-based MosquitoMate has field-tested the technology on A. albopictus in three states in the US. The company is awaiting registration, or approval, from the
US Environmental Protection Agency (EPA). A similar technology developed by a consortium of Chinese researchers in 2015 was field tested in A. albopictus in Guangzhou, China, and another test is planned for this year.

Furthest along is the genetically modified (GM) mosquito from Oxitec. The transgenic A. aegypti (OX513A) mosquito carries a gene encoding tetracycline-repressible transcription activator (tTA), a protein whose high-level expression is deleterious to cellular development. If the mosquitoes are grown in the presence of tetracycline, however, it binds and represses tTA expression, allowing batches of transgenic mosquitoes to be grown (whereas in the absence of the antibiotic, transgenic mosquito larvae die). The smaller male pupae are sorted from the female and released into the environment to mate with wild females, resulting in progeny that die before reaching reproductive stage (Nat. Biotechnol. 29, 9-11, 2011).

Oxitec, now a subsidiary of Intrexon of Germantown, Maryland, says OX513A mosquitoes reduced the wild mosquito population by $80-95 \%$ in field trials in Panama, the Cayman Islands and Juazeiro, in the Brazilian state of Bahia (PLOS Negl. Trop. Dis. 9, e0003864, 2015). Unlike insecticides traditionally used for vector control, Oxitec mosquitoes can easily get inside private properties, where much of the vector problem persists. "The male mosquito will always find the female. It doesn't have to ask permission to enter the house," says Hadyn Parry, CEO of Oxitec. 


\begin{tabular}{|c|c|c|}
\hline Company & Therapeutic modality/description & Status \\
\hline Sanofi Pasteur (Lyon, France) & $\begin{array}{l}\text { Intends to leverage its ChimeriVax live, attenuated recombinant } \\
\text { vaccine constructed from yellow fever expressing envelope genes of } \\
\text { target viruses, with other vaccine approaches }\end{array}$ & Developing a timeline for the start of clinical trials \\
\hline $\begin{array}{l}\text { Butantan Institute } \\
\text { (São Paulo, Brazil) }\end{array}$ & $\begin{array}{l}\text { Two candidate vaccines: inactivated vaccine (in development at } \\
\text { Butantan Institute) and live attenuated vaccine in partnership with } \\
\text { the US National Institutes of Health }\end{array}$ & Zika virus growth \\
\hline NIAID & $\begin{array}{l}\text { DNA-based vaccine based on approach to West Nile virus vaccine } \\
\text { and a live-attenuated vaccine based on approach to dengue virus }\end{array}$ & Preclinical \\
\hline $\begin{array}{l}\text { Inovio Pharmaceuticals } \\
\text { (Plymouth Meeting, } \\
\text { Pennsylvania) \& GeneOne Life } \\
\text { Science (Seoul, South Korea) }\end{array}$ & DNA vaccines encoding for surface and/or capsid proteins & $\begin{array}{l}\text { Entered preclinical studies in } 4 Q 2015 \text {. Phase } 1 \text { clinical } \\
\text { study planned to be initiated in } 4 Q 2016\end{array}$ \\
\hline $\begin{array}{l}\text { Hawaii Biotech (Honolulu, } \\
\text { Hawaii) }\end{array}$ & $\begin{array}{l}\text { Viral recombinant subunit proteins resulting in nonreplicating } \\
\text { vaccines }\end{array}$ & Preclinical \\
\hline $\begin{array}{l}\text { Protein Sciences Corporation } \\
\text { (Meriden, Connecticut) }\end{array}$ & Recombinant protein & $\begin{array}{l}\text { Expects to initiate human clinical studies within the next two } \\
\text { months }\end{array}$ \\
\hline Jenner Institute (Oxford, UK) & $\begin{array}{l}\text { Subunit vaccine consisting of a nonreplicating recombinant simian } \\
\text { adenovirus encoding the surface protein(s) of Zika virus }\end{array}$ & Planning to enter preclinical studies in April 2016 \\
\hline $\begin{array}{l}\text { NewLink Genetics (Ames, } \\
\text { lowa) }\end{array}$ & Non-live, nonreplicating, whole virus particle vaccine & Undisclosed \\
\hline $\begin{array}{l}\text { Bharat Biotech (Hyderabad, } \\
\text { India) }\end{array}$ & $\begin{array}{l}\text { Two candidates: one inactivated vaccine, and the other recombinant } \\
\text { using surface antigens of the virus }\end{array}$ & Preclinical testing in animals \\
\hline PaxVax & Various virus-like particle vaccine candidates & Preparing for preclinical animal studies \\
\hline
\end{tabular}

The company in 2014 received approval from Brazil's National Technical Commission of Biosecurity (CTNBio) to commercialize the GM mosquito. But before the OX513A mosquitoes reach the market, the Health Surveillance Agency (Anvisa) must issue labeling and guidance. In the meantime, the city of Piracicaba, in the state of São Paulo, has taken matters into its own hands. The city first partnered with Oxitec in April 2015 to release the GM mosquitoes in a neighborhood of about 5,000 people. The program reduced the larvae population by $82 \%$ compared to an untreated area, according to the company. In January, the partners announced they would expand the project to an area covering 60,000 people, and that Oxitec would build a local facility to rear enough mosquitoes to cover 300,000 people.

Other Brazilian officials have said they are interested OX513A. Local news organizations in Vitória, a coastal city in the state of Espírito Santo, in December reported that health officials there and in nearby Vila Velha were considering the approach. Neither city, however, has pulled the trigger. Such a move is difficult without guidance from Anvisa and state authorities on the protocols for deploying the mosquitoes and how to integrate them with insecticides. "If you're a municipal secretary of health and you've got a limited budget, it's quite tricky, because you've got to follow the established rules and policies so that your back is covered by the state," says Parry. That's true for Piracicaba too. "We will need resources from other levels of government," to continue scaling up the project, says Gabriel Ferrato, the mayor of Piracicaba. Many Brazilian cities lack the resources to do both traditional mosquito prevention and a new technology like Oxitec's, he says.

Several independent researchers contacted by Nature Biotechnology said Oxitec's technology is intriguing and worth pursuing. "I think it's really important to look at this and see where it can go," says Fred Gould, an entomologist at North Carolina State University in Raleigh. "Even if it only worked in specific, smaller cities, that's one piece of the puzzle."

Gould and others noted that neither Oxitec's nor any other approach alone is going to fix a global problem like Zika. Pesticides, sanitation, water infrastructure, public education, biotech-all of it-must be deployed, and in ways that are tailored to local environments, adds Margareth Capurro, a biochemist at the University of São Paulo in Brazil, who was commissioned by Oxitec's partner, Brazilian state-owned Moscamed, to study the mosquitoes.

Oxitec's technology presents some unknowns. It is unclear how easily production could be ramped up, or how well it would perform on a large scale. "There are no studies on the cost-benefit" of Oxitec's technology on a large scale, says Ferrato. Transporting large numbers of mosquitoes to their destinations could be a logistical obstacle and a considerable expense. In Piracicaba, Oxitec employees drove around in vans releasing mosquitoes through the windows to get them close to people's homes. And even if mosquito populations are reduced drastically, it's not clear what effect that will have on transmission of Zika. It seems logical that reducing the vector would decrease disease, but other factors come into play, says Scott at UC Davis. For example, if a population of people has no immunity to a virus "you can have very few mosquitoes and have an outbreak," he says.

Carlos Brisola Marcondes, an entomologist at Federal University of Santa Catarina in Brazil, says it concerns him that most of the data about OX513A has come from Oxitec and its partners. "It would be advisable to get independent evaluations" that don't involve Oxitec at all, he says. Marcondes says he would like to see large-scale studies, ecological assessments and cost analyses made before the technology is adopted.

With a virus as unstudied as Zika spreading explosively, officials are calling for a global full-court press from researchers. To that end, Capurro is leading a group of 40 scientists funded by the Brazilian government who will study how mosquitoes transmit the virus. And Marques in February headed to Brazil to join a research coalition called the Microcephaly Epidemic Research Group (MERG) studying the link between Zika and microcephaly, and to search for any co-factors that may contribute (Nature 530, 142143, 2016). "It may be Zika plus something else" that causes microcephaly, Marques says.

Emily Waltz Nashville, Tennessee 